\title{
Farklı Yaşlardaki Tüplü Fıstıkçamı (Pinus pinea L.) Fidanlarının Morfolojik Kalite Özellikleri
}

\author{
Sezgin AYAN ${ }^{*}$, Emre CIVEK ${ }^{2}$, Esra Nurten YER ÇELIK ${ }^{1}$, Orhan GÜLSEVEN ${ }^{3}$, Halil Barış \\ ÖZEL ${ }^{4}$, Jeuma Ahmed Hamed ESHAIBI ${ }^{3}$, Şeyma Selin AKIN $^{3}$, Ergin YILMAZ ${ }^{3}$ \\ ${ }^{1}$ Kastamonu Üniversitesi, Orman Fakültesi, Silvikültür ABD, 37000, KASTAMONU \\ ${ }^{2}$ Bursa Orman Bölge Müdürlüğü, Bursa Orman Fidanlık Müdürlüğü, 16010, BURSA \\ ${ }^{3}$ Kastamonu Üniversitesi, Fen Bilimleri Enstitüsü, Orman Mühendisliği ABD, 37000, KASTAMONU \\ ${ }^{4}$ Bartın Üniversitesi, Orman Fakültesi, Silvikültür ABD, 74100, BARTIN
}

\section{Öz}

Samsun-Gelemen Orman Fidanlığında yürütülen çalışmada, Samsun orijinli farklı yaşlardaki tüplü fistıkçamı (Pinus pinea L.) fidanlarının morfolojik kalite özelliklerinin belirlenmesi amaçlanmıştır. Bu amaçla fidanların morfolojik özelliklerini belirlemede; Kök boğazı çapı (KBÇ), fidan boyu (FB), terminal sürgün boyu (TSB), kök taze ağırlığı (KTA), gövde taze ağırlığı (GTA), kök kuru ağırlığı (KKA), gövde kuru ağırlığı (GKA), fidan kuru ağırlığı (FKA), gürbüzlük indisi (Gİ), kuru kök yüzdesi (\%KKök), katllık indisi (Kİ) ve Dickson kalite indeksi (DKI) kriterleri baz alınmıştır. Tespit edilen morfolojik özelliklere göre fidanlar, Türk Standartları Enstitüsü (TSE) kriterleri ve Aphalo ve Rikala (2003) GI değerine göre değerlendirilmiş̧ir. Yetiştirilen $2+0$ ve $3+0$ yaşlı polietilen tüplü fidanların morfolojik kalite özellikleri ortalamaları sırasıyla; KBÇ: 7,92-11,8 mm; FB: 39,06-65,3 cm; TSB: 15,93-31,77 cm; KTA: 6,59-14,26 gr; GTA: 31,99-85,42 gr; KKA: 2,54-6,18 gr; GKA: 12,09-33,84 gr; FKA:14,63-40,02 gr; Gİ: 49,01-56,44; \%KKök: 17-16; Kİ:4,99-5,61; DKİ:1,5-3,65 olarak belirlenmiștir. Kİ kriteri açısından $2+0$ yaşlı fidanların \%76,7'si, 3+0 yaşlı fidanların ise \%90'1 "Iskarta" vasfindadır. Mevcut morfolojik standarttaki fidanların sadece peyzaj amaçlı ağaçlandırma çalışmalarında kullanılabileceği düşünülmektedir.

Anahtar Kelimeler: Samsun-Gelemen, fidan morfolojisi, kallite sınıfi, TSE, fistıkçamı.

\section{Morphological Quality Characteristics of Different Ages Containerised Seedlings of Stone Pine (Pinus pinea L.)}

\begin{abstract}
It was aimed to determine the morphological quality characteristics of containrised stone pine (Pinus pinea L.) seedlings originated from Samsun at different ages in this study performed in Samsun-Gelemen Forest Nursery. For this purpose, Root collar diameter (RCD), seedling height (SH), the lenght of terminal shoot (LTS), root fresh weight (RFW), stem fresh weight (SFW), root dry weight (RDW), stem dry weight (SDW), seedling dry weight (SEDW), sturdiness index (SI), dry root percentage (DR\%) shoot-root ratio (SRR) and Dickson Quality Index (DQI) criteria were choosed for detectioning morphological characteristics of the seedlings. According to the morphological characteristics identified, seedlings were evaluated in terms of Turkish Standart Institute (TSI) criterias and the SI values of Aphalo and Rikala (2003). Morphological quality characteristics of grown $2+0$ and 3+0 aged polyethylene containerised seedlings were determined as RCD: 7,92-11,8 mm; SH: 39,06-65,3 cm; LTS: 15,93-31,77 cm; RFW: 6,59-14,26 gr; SFW: 31,99-85,42 gr; RDW: 2,54-6,18 gr; SDW: 12,09-33,84 gr; SEDW:14,63-40,02 gr; GI: 49,01-56,44; DR\%: 17-16; SRR:4,99-5,61; DQI: 1,5-3,65 respectively. 76.7\% of 2+0 aged, and $90 \%$ of $3+0$ aged seedlings in terms of KI criteria is "unsuitable". It is thought that seedlings of the current morphological standard can only be used in afforestation for landscaping purposes.
\end{abstract}

Keywords: Samsun-Gelemen, seedling morphology, quality class, TSI, stone pine.

*Sorumlu Yazar (Corresponding Author):

Sezgin AYAN (Dr.); Kastamonu Üniversitesi, Orman Fakültesi, Orman Mühendisliği

Bölümü, Kuzeykent Kampüsü, 37000, Kastamonu-Türkiye. Tel: +90 (366) 2801733

E-mail: sezginayan@gmail.com ORCID: 0000-0001-8077-0512
Geliş (Received) : : 16.04.2020

Kabul (Accepted) : 20.05.2020

Basım (Published) : 15.08.2020 


\section{Giriş}

Fıstıkçamı (Pinus pinea L.), Portekiz'den Suriye'ye kadar olan kısımda, Karadeniz'in bazı kıyı bölgelerinde, kuzey ve doğu Akdeniz'de yayılış göstermektedir. Kuzey Akdeniz'de 500-600 m ve Doğu Akdeniz'de 800-1400 m'ye kadarki yükseltilerde görülebilmektedir. Karakteristik olarak thermo ve meso Akdeniz iklim zonlarında (Fady vd., 2004) yaklaşı 620.000 ha saf ya da karışı halde fistıkçamı ormanları mevcuttur (Garcia vd., 2000). Çoğunlukla saf meşcereler kuran, genetik olarak çok üniform ve diğer çam türleriyle hibrit yapmayan fistıkçamı (Fady vd., 2004), Dünya'da İspanya, Portekiz, İtalya, İsrail, Yunanistan, Fas, Cezayir ve Tunus başta olmak üzere, Akdeniz ekosistemindeki bölgelerde doğal ya da ağaçlandırma yoluyla varlı̆̆ını sürdürmektedir (Fırat, 1943). Fıstıkçamının, çoğunlukla Tunus, Cezayir ve Fas olmak üzere Kuzey Afrika ile Arjantin ve Güney Afrika gibi ülkelerde başarılı bir şekilde introdüksiyonu gerçekleştirilmiş̧ir. Örneğin; Kaliforniya, İskoçya, Güney İngiltere gibi yerlerde ise genellikle parklar ve bahçelerle sınırlı bir plantasyonu söz konusudur. Ekonomik önemi nedeniyle coğrafi ve genetik çeşitliliğindeki mevcut aktüel dağılışında güçlü insan etkisinin var olduğu açıktır. Pinus pinea (eski adıyla Pinus domestica), yenilebilir tohumları nedeniyle Etrüskler, Yunanlılar, Romalılar ve Araplar tarafindan tarihi zamanlar boyunca Akdeniz'in etrafina yoğun bir şekilde dikilmiştir (Fady vd., 2004). Anadolu, Lübnan, Kıbrıs, Yunanistan ve İber Yarımadası en muhtemel orijinal bölgeleridir (Quézel and Médail, 2003; Fady vd., 2004; Farjon, 2013). Kozalak ve odun kömürü parçalarından fistıkçamının, İspanyol paleolitik yerleşimlerinde 50.000 y1l önce var olduğu belirtilmektedir. Roma döneminden bu yana inşaat ve gemi yapımı için kereste üretimi amaçlı kültivasyonu yapılıyor olmasına rağmen, ekonomik olarak en önemli ürünü tohumu, çam fistı̆̆ıdır (Fady vd., 2004; Carrasquinho ve Gonçalves, 2013) İspanya, Portekiz, İtalya, Tunus ve Türkiye gibi ülkeler çam fistığının geleneksel olarak pazarlandığı ana ülkelerdir. Ekonomik değere sahip diğer ürünleri arasında reçine ve tanen ekstraksiyonu amaciyla kullanılan kabuğu da yer almaktadır (Fady vd., 2004). Son 30 yılda özel arazi sahipleri, çam fistığı için ödenen yüksek fiyatların teşviki dolayısıyla kozalak üretimine yönelik yeni fistıkçamı plantasyonlarına 20 milyon avrodan fazla yatırım yapmışlardır. Portekiz ve Türkiye, genellikle orman arazisinden daha yüksek miktardaki kozalak hasadını terk edilmiş tarım arazilerinden $(0,25$ milyon hektardan fazla yeni plantasyon) gerçekleştirmektedir (Calado, 2012; Mutke vd., 2012; Kılcı vd., 2014). Halen Akdeniz çevresinde yaygın olan fistıkçamının kıyı kumullarının stabilizasyonu, toprak koruma ve kıyı tarımsal ürünlerin korunması ile çevre koruma ve ekosistem restorasyonu amaçlı plantasyonu yapılmaktadır (Awada vd., 2003; Fady vd., 2004; Mutke vd., 2011).

Tipik Akdeniz ağacı olan fistıkçamı (Ganatsas vd., 2008), Türkiye'deki beş doğal çam türünden biridir. Türkiye ormanlarının 33.742 hektarını saf ve karışık haldeki doğal fistıkçamı ormanları oluşturmaktadır. Ağaçlandırma çalışmaları ile tesis edilen toplam fistıkçamı alanı ise yaklaşık 59.150 hektardır (OGM, 2006). Fıstıkçamı, batı Anadolu'da Bergama/Kozak, Aydın/Koçarlı ve Muğla dolaylarında en geniş yayılışını yapmaktadır (Fırat, 1943; Yaltırık, 1988). Yeni ağaçlandırmalar ile toplam fistıkçamı alan miktarının sürekli artığı tahmin edilmektedir. Çamfistığı, Türkiye'de günar, kuner (Denizli), küna, künar, küner, püste (Anonim, 2013), kozalağına çedene (Kahramanmaraş) (Avşar, 2000) gibi yöresel adlar ile bilinmektedir.

Fıstıkçamı popülasyonları, özellikle kuraklık gibi diğer çevresel streslerle birleştirildiğinde hava kirliliğine karşı oldukça hassastır (Fady vd., 2004). Kuraklık stresi, Akdeniz karasal iklim bölgelerinde bitki yaşamı için önemli bir kısıtlayıcı faktördür (Villar-salvador vd., 2013). Fıstıkçamı yaz kuraklıklarına karşı çok toleranslı olarak kabul edilmektedir (Carrasquinho ve Gonçalves, 2013). Yılmaz vd. (2010) de fistıkçamının, Akdeniz ikliminde yüksek sıcaklıklara ve kuraklığa iyi adapte olabildiğine vurgu yapmaktadırlar. Ancak, Ürgenç (1986) Türkiye'de Güneydoğu Anadolu'da yapılan 7 yıllık araştırma sonuçlarına dayanarak, yılda $400 \mathrm{~mm}$ yağıştan daha az olan yerlerin fistıkçamı için uygun olmadığı ve dolayısıyla önerilmediğini bildirmektedir. Deligöz ve Gür (2015) fistıkçamının kuraklık stresine karşı morfolojik, fizyolojik ve biyokimyasal tepkilerini inceledikleri çalışmada; iğne yapraklarda biriken prolin miktarındaki artış ve ozmotik ayarlamanın, fistıkçamının kuraklık stresine toleransını artıran bir olay olduğunu, iğne yapraklardaki prolin birikimi yoluyla ozmotik potansiyeli azaltarak, ozmotik ayarlama ve kuraklığa dayanıklı büyümenin azaltılması yoluyla birçok önemli mekanizmalar kullandığını belirtmişlerdir. Buna rağmen, Sayman vd. (2006) fistıkçamının kurak ve yarı kurak bölgeler için uygun bir tür olmadığını bildirilmektedir.

Türün ekolojik, estetik ve ekonomik değeri ve düşük yoğunluklu yangınlara dayanma kabiliyeti, bu türü çok amaçlı ormancıllk ve doğa koruma için çok önemli kılmaktadır (Ganatsas vd., 2008; Kırdar vd., 2010). Yunanistan'da yapılan araştırmalarda, fistıkçamında doğal gençleşmenin yokluğu ve Halep çamının fistıkçamı alanlarına işgali yıllardır gözlenmektedir (Barbero vd., 1998; Moussouris ve Regato, 1999; Tapias vd., 2004). Doğal gençleşmenin 
olmayış1 veya düşüklüğü, tohum ağaçlarının ürettiği tohumların yetersizliği, ki bu son yıllarda gittikçe düşmektedir, sınırlı tozlaşma ve tohum kalitesinin düşüklüğünden kaynaklanabilmektedir (Lawerence, 1993; Ramsey, 1997; Bazzaz vd., 2000). Ayrıca, Yunanistan'daki yangınlar ile azalan fistıkçamı ormanlarının (Rodrigo vd., 2007) yangın öncesi duruma dönüştürülmeleri olası gözükmediğinden fistıkçamı ekosistemlerini restore etmek için eylem planları önerilmektedir (Perula vd., 2003).

Tarımsal ormancılık uygulamalarında fıstıkçamının önemi, peyzaj düzenlemelerinde tercih edilmesi, doğal ormanlardaki gençleşme güçlükleri, yayılış sahasındaki kuraklık kısıtlayıcı faktörü ve iklim değişikliğinin özellikle Akdeniz havzasındaki etkileri bir bütün olarak değerlendirildiğinde fistıkçamı için kaliteli fidan üretimi; plantasyon, rejenerasyon ve restorasyon çalışmalarının başarısında önemli rol oynayan faktörlerden biri olacaktır. Türkiye fidanlıklarında yapılan fidan kalitesi araştırmalarında gerek ekonomik gerek zaman tasarrufu dikkate alınarak morfolojik fidan kalitesi tayinine yönelik araştırmalar yürütülmüştür. Türkiye'de bu anlamda, karaçam (Kızmaz, 1993; Ayıntaplı, 1995; Avanoğlu vd., 2005; Deligöz, 2007; Yer ve Ayan, 2011), sarıçam (Demircioğlu vd., 2004), Toros sediri (Eler vd., 1993; Ayıntaplı, 1995; Yer ve Ayan, 2011; Çetinkaya ve Bilir, 2019), Doğu kayını (Gülseven vd., 2019) ve Doğu ladini (Gezer, 1976; Genç, 1992; Ayan, 2002) gibi orman ağacı türlerinde fidan kalite sınıflandırılması üzerine detaylı birçok çalışma gerçekleştirilmiştir.

Bu çalışmada; kuraklık, tuzluluk gibi abiyotik stres faktörlerine karşı dayanıklı (Gilman ve Watson, 1994) olan ve kumul stabilizasyonunda başarılı bir şekilde kullanılan (Gezer ve Aslan, 1980; Genç, 2004), hızlı büyüme özelliği ile endüstriyel plantasyon çalışmalarında önemli olan (Ayan ve Sıvacıoğlu, 2006) ve rekreasyonel değeri nedeniyle peyzaj düzenleme çalışmalarında kullanılan fıstıkçamı araştırma materyali olarak kullanılmıştır. Çalışmada; Samsun-Gelemen orman fidanlığı ekolojisinde yetiştirilen tüplü fistıkçamı fidanlarının morfolojik özellikleri incelenerek, Türk Standartları Enstitüsü kalite kriterleri ve Aphalo ve Rikala (2003) gürbüzlük indisi değerlerine göre kalite sınıfları incelenmeye çalışılmıştır.

\section{Materyal ve Metot}

\subsection{Materyal}

Çalışma, 2015-2018 yıllarında Samsun-Gelemen Orman Fidanlığında yürütülmüştür. Fidanlığın genel özellikleri tablo 1'de verilmiştir. Fidan üretiminde Samsun-Gelemen orman fidanlığı içerisindeki ağaçlardan elde edilen tohumlar kullanılmıştır. Araştırma objesi olarak, Samsun orijinli $2+0$ ve $3+0$ yaşlı polietilen tüplü $(15 \times 30 \mathrm{~cm})$ fıstıkçamı fidanları kullanılmıştır.

Tablo 1. Samsun-Gelemen Orman Fidanlığ ile ilgili genel bilgiler.

\begin{tabular}{|c|c|c|c|}
\hline Özellikler & Değerler & Özellikler & Değerler \\
\hline Enlem & $40^{\circ} 50^{\prime}-41^{\circ} 51^{\prime}$ & Y1llık ortalama sicaklık $\left({ }^{\circ} \mathrm{C}\right)$ & $+14,7$ \\
\hline Boylam & $37^{\circ} 08^{\prime}-34^{\circ} 25^{\prime}$ & $\begin{array}{l}\text { Yillik maksimum sicaklik } \\
\left({ }^{\circ} \mathrm{C}\right)\end{array}$ & $+39,7$ \\
\hline Bakı & Kuzeydoğu & Y1llı minimum sicaklık $\left({ }^{\circ} \mathrm{C}\right)$ & $-12,5$ \\
\hline Rakım (m) & 5 & Y1llık yağgiș (mm) & 741,8 \\
\hline Tekstür & Kumlu killi balçık & Yıllık ortalama bağıl nem (\%) & 74,73 \\
\hline pH & 7,3 & Vejetasyon dönemi & Mart-Kasim \\
\hline Kireç (\% $\left.\mathrm{CaCO}_{3}\right)$ & 3,5 & Toplam azot (mg/L) & 0,12 \\
\hline Organik madde (\%) & 2,3 & $\mathrm{P}_{2} \mathrm{O}_{5}(\mathrm{ppm})$ & 53,8 \\
\hline
\end{tabular}

\subsection{Yöntem}

\subsubsection{Fidan üretimi}

Kozalaklar, Samsun-Gelemen orman fidanlığındaki fistıkçamı ağaçlarından Mart-Nisan aylarında toplanmış ve sundurma altında naylonların üzerinde 2-2,5 ay süreyle kurutulup, tohumları çıkartılmıştır. Suda yüzdürme yöntemi ile boş tohumlar ayıklandıktan sonra tohumlar, hazırlanan kaplı üretim yastıklarında direkt olarak polietilen tüplere 2015 ve 2016 yılları Nisan ayında ekim yapılmıştır. Tüp harc1 olarak, 2:1:1 oranlarında toprak, 
humus ve ponza karışımı hazırlanmış, her tüpe 2-3 adet tohum ekilerek, çimlenmeden 2 ay sonra tekleme işlemi yapılmıştır. Tüplü fidanlara yılda $2 \mathrm{kez}$ Nisan ve Mayıs aylarında $\% 21$ amonyum sülfat gübresi uygulanmış ve Nisan-Eylül aylarında 5 defa ot bakımı yapılmıştır. Hava durumu ve gözleme dayalı olarak yağmurlama sulama sistemi ile rutin sulama programı uygulanmıştır.

\subsubsection{Morfolojik ölçümler}

Kaplı fidan üretim yastıklarından tesadüfi ve üç tekrarlı olarak örneklenen 30'ar fidan, vakit kaybedilmeden laboratuvara götürülüp, ölçümleri yapılmıştır. Taze fidanların; fidan boyu (FB) ve kök boğaz çapları (KBÇ) ile daha sonra kök boğazından kesilerek gövde ve kök taze ağırlıkları (GTA, KTA) ve terminal sürgün boyu (TSB) ölçülmüştür. Ölçümleri tamamlanan fidanlar etüve alınarak $105^{\circ} \mathrm{C}$ 'de 24 saat bekletilmiş, gövde ve kök kuru ağırlıkları (GKA, KKA, FKA) ölçümleri yapılmıştır.

Elde edilen veriler yardımıyla aşağıdaki karakterler hesaplanmıştır:

- $\quad$ Kuru kök \% (\%Kkök) = [KKA(g) / FKA (g)] x 100 (Ayan, 1999),

- $\quad$ Katlll1k indisi (Kİ) = GKA/KKA (Thompson, 1985),

- $\quad$ Dickson kalite indeksi (DKİ) =Fidan kuru ağırlık değerinin, Gürbüzlük indisi ile katlılık değeri toplamına bölünmesi ile elde edilen değerdir. Aşağıda belirtilen formül aracılı̆̆ı ile hesaplanmıştır (Dickson vd., 1960).

$$
\mathrm{DKI}=\frac{\text { Fidan Kuru Ağırlığı }}{(\text { Gürbüzlük İndisi })+(\text { Katlılık indisi })}=\frac{\mathrm{FKA}}{\left(\frac{\mathrm{FB}}{\mathrm{KBÇ}}\right)+\left(\frac{\mathrm{GKA}}{\mathrm{KKA}}\right)}
$$

- $\quad$ Gürbüzlük indisi (Gí) $=[\mathrm{FB}(\mathrm{mm}) / \mathrm{KBÇ}(\mathrm{mm})]$ (Aphalo ve Rikala, 2003),

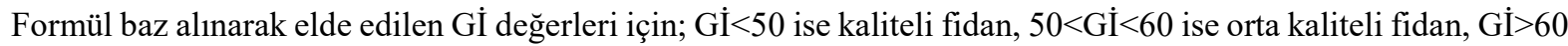
ise düşük kaliteli fidan aralıklarına göre sınıflandırma yapılmıştır (Aphalo ve Rikala, 2003). Ayrıca, fidanların kalite sınıflarının belirlenmesi amacı ile iğne yapraklı türlerin kalite sınıfları kullanılarak TS 2265/Şubat 1988 TSE standartlarına uygunluğu değerlendirilmiştir (Tablo 2).

Tablo 2. TS 2265/Şubat 1988 standartlarına göre fistıkçamı fidan kalite sınıfları (Anonim 1988)

\begin{tabular}{|c|c|c|c|}
\hline \multirow[t]{2}{*}{ Fidan Sinıfi } & \multicolumn{3}{|l|}{ Fistıkçamı } \\
\hline & Fidan Boyu (cm) & Kök Boğazı Çapı (mm) & Gövde/Kök \\
\hline & $2+0$ yaşlı & & \\
\hline I & $\geq 18.0$ & \multirow{2}{*}{$\geq 2.0$} & $<3$ \\
\hline II & $15.0-17.9$ & & $3-4$ \\
\hline \multirow[t]{2}{*}{ Iskarta } & $<15.0$ & $<2.0$ & $>4$ \\
\hline & 3+0 yaşlı & & \\
\hline I & $\geq 30.0$ & \multirow{2}{*}{$\geq 2.0$} & $<3$ \\
\hline II & $25.0-29.9$ & & $3-4$ \\
\hline Iskarta & $<25.0$ & $<2.0$ & $>4$ \\
\hline
\end{tabular}

\subsection{3. İstatistiki Değerlendirme}

Fidanlarda ölçülen FB, TSB, KBÇ, GTA, KTA, GKA ve KKA değerleri ile hesaplanan FKA, Gİ, Kİ, \%Kkök ve DKİ değerleri üzerinde temel istatistikler (ortalama, standart sapma, standart hata, minimum ve maksimum değerler, değişim aralıkları) SPSS paket programı aracılığı ile hesaplanmıştır.

\section{Bulgular ve Tartışma}

Fidanlarda yapılmış olan KBÇ, FB, TSB, KTA, GTA, KKA, GKA, FKA, Gİ, \%KKök, Kİ ve DKİ morfolojik özelliklerine ait temel istatistikler Tablo 3'de verilmiştir. Gİ değeri haricinde ölçülen ve hesaplanan bütün morfolojik kriterlerin değerlerinde yaşa bağlı müspet bir artış tespit edilmiştir. Tablo 3'den görüleceği üzere ölçülen birçok morfolojik özellik bakımından değişim aralığının yüksek olması, fidan üretiminde yüksek bir heterojenitenin var olduğunu göstermektedir. Sözgelimi; 1+0 yaşlı tüplü fidanlardaki değişim aralığı; KBÇ’ında $11 \mathrm{~mm}$, FB'nda 23 cm, GTA'1nda 56,98 gr, FTA'nda 68,77 gr, GKA'nda 22,37 gr, FKA'nda 28,3 gr, GI'nde 36,5, Kİ'nde 4,28 ve DKI'nde 3,74; 2+0 yaşlı tüplü fidanlarda ise KBÇ'nda 8,8 mm, FB'nda 26 cm, KTA'nda 
21,4 gr, GTA'nda 164,29 gr, FTA'nda 182,98 gr, GKA'nda 66,23 gr, FKA'nda 75,22 gr, Gİ'nde 35,34, Kİnde 6,9 ve DKİ'nde 6,98 olması örnek olarak verilebilir. Bilir vd. (2010) 15 farklı açık tozlaşma ürünü ailelerin tohumlarıyla fıstıkçamında yürüttüğü araştırmada, morfolojik özellikler bakımından aileler arasında geniş varyasyonlar olduğunu bu durumun, tohum hasadında bireysel seleksiyonun kitlesel seleksiyondan daha ön plana çıktığına vurgu yapmışlardır.

Tablo 3. Fıstıkçamı fidanlarının yaşlara göre morfolojik karakterlerinin temel istatistikleri.

\begin{tabular}{|c|c|c|c|c|c|c|c|c|c|c|c|c|}
\hline \multirow[b]{2}{*}{ Morfolojik Karakter } & \multicolumn{6}{|c|}{ 2+0 Yaşlı Tüplü } & \multicolumn{6}{|c|}{ 3+0 Yaşlı Tüplü } \\
\hline & Ort. & $\begin{array}{l}\text { Std. } \\
\text { hata }\end{array}$ & $\begin{array}{c}\text { Std. } \\
\text { sapma }\end{array}$ & Min. & Max. & $\begin{array}{c}\text { Değişim } \\
\text { aralığı }\end{array}$ & Ort. & $\begin{array}{c}\text { Std. } \\
\text { hata }\end{array}$ & $\begin{array}{c}\text { Std. } \\
\text { sapma }\end{array}$ & Min. & Max. & $\begin{array}{c}\text { Değişim } \\
\text { aralığı }\end{array}$ \\
\hline Kök boğazı çapı (mm) & 7,92 & 0,39 & 2,19 & 1,00 & 12,00 & 11,00 & 11,8 & 0,361 & 1,98 & 8,40 & 17,20 & 8,80 \\
\hline Fidan Boyu (cm) & 39,06 & 0,92 & 5,009 & 23,00 & 46,00 & 23,00 & 65,3 & 1,32 & 7,25 & 53,00 & 79,00 & 26,00 \\
\hline Terminal sürgün boyu (cm) & 15,93 & 0,48 & 2,6 & 11,00 & 21,00 & 10,00 & 31,77 & 1,07 & 5,84 & 21,00 & 47,00 & 26,00 \\
\hline Kök taze ağırlığı (gr) & 6,59 & 0,54 & 2,97 & 2,27 & 14,29 & 12,02 & 14,26 & 1,00 & 5,492 & 6,48 & 27,88 & 21,40 \\
\hline Gövde taze ağırlığı (gr) & 31,99 & 2,59 & 14,23 & 10,12 & 67,10 & 56,98 & 85,42 & 6,81 & 37,31 & 30,86 & 195,15 & 164,29 \\
\hline Fidan taze ağırlığı (gr) & 38,59 & 3,1 & 16,99 & 12,62 & 81,39 & 68,77 & 99,68 & 7,67 & 41,98 & 37,34 & 220,32 & 182,98 \\
\hline Kök kuru ağırlığı (gr) & 2,54 & 0,26 & 1,406 & 0,54 & 6,47 & 5,93 & 6,18 & 0,46 & 2,54 & 2,42 & 12,96 & 10,54 \\
\hline Gövde Kuru ağırlığı (gr) & 12,09 & 1,05 & 5,73 & 3,50 & 25,87 & 22,37 & 33,84 & 2,74 & 14,99 & 13,08 & 79,31 & 66,23 \\
\hline Fidan Kuru Ağırlığı (gr) & 14,63 & 1,28 & 7,035 & 4,04 & 32,34 & 28,30 & 40,02 & 3,08 & 16,86 & 15,50 & 90,72 & 75,22 \\
\hline Gürbüzlük İndisi & 49,01 & 1,73 & 9,48 & 37,5 & 74 & 36,5 & 56,44 & 1,65 & 9,08 & 41,01 & 76,43 & 35,34 \\
\hline Kuru Kök \% & 0,17 & 0,0059 & 0,032 & 0,12 & 0,25 & 0,13 & 0,16 & 0,008 & 0,041 & 0,10 & 0,32 & 0,22 \\
\hline Katlılık & 4,99 & 0,2 & 1,096 & 3,03 & 7,31 & 4,28 & 5,61 & 0,26 & 1,41 & 2,16 & 9,06 & 6,90 \\
\hline DKİ & 1,50 & 0,17 & 0,921 & 0,39 & 4,13 & 3,74 & 3,65 & 0,30 & 1,66 & 1,28 & 8,26 & 6,98 \\
\hline
\end{tabular}

Bu çalışmada; 2+0 yaşlı tüplü fidanlarda ortalama boy 39,06 cm, KBÇ 7,92 mm, katlılık 4,99 ve DKİ 1,5 olarak tespit edilirken, Bilgin (2019) tarafından İzmir, Torbalı orijinli, 2+0 yaşlı tüplü fistıkçamı fidanları üzerinde yapılan çalışmada 21,02 cm boy, $5.4 \mathrm{~mm}$ çap ve 1,05 katlılık ve 0,15 DKİ değerleri belirlenmiştir. Aynı yaştaki tüplü fidanlar arasındaki bu büyük farkın sebeplerinden en önemlilerinden biri kullanılan tüplerin boyutlarının aynı olmamasından kaynaklandığı söylenebilir. Zira, tarafımızca yürütülen bu çalışmada $15 \times 30 \mathrm{~cm}$ boyutlarındaki polietilen tüp kullanılırken, Bilgin (2019) tarafından yürütülen çalışmada $12 \times 22,5 \mathrm{~cm}$ boyutlarındaki tüp kullanılmıştır. Ayrıca, bu araştırmanın yürütüldüğü Samsun-Gelemen orman fidanlığında y1lda iki kez uygulanan \%21'lik amonyum sülfat gübrelemesi fidanların bilhassa FB ve GTA değerlerinin artmasına sebep olduğu düşünülmektedir. Bilgin (2019) çalışmasında 1,05 değerinde, Bilgin (2008) çalışmasında ise çoğunlukla 2 değerinde kök-gövde dengesi uygun fidanlar elde edilirken, yürütülen bu çalışmada $2+0$ yaşlı fidanlarda Kİ 4,99, 3+0 yaşlı fidanlarda ise Kİ 5,61 olarak bulunmuştur. Bu sonuç, Samsun-Gelemen orman fidanlığında fidan gövde gelişimini aşırı bir şekilde tetikleyen uygulamaların (sulama, gübreleme, sık yetiştirme vb gibi) olduğunu teyit etmektedir. Bilgin (2008) çalışmasında; farklı orijinlerin (Kozak ve Koçarlı), 5 farklı yetiştirme ortamı ve farklı hacimdeki 5 değişik kap tipinde yetiştirilen fistıkçamı FB'larının 9,00-22,13 cm, KBÇ'larının 2,86-6,03 mm aralığında oldukça büyük bir varyasyonda olduğunu tespit etmişlerdir. Dominguez Lerena vd. (2006), İspanya'da 16 çeşit kap tipinde, \%80 turba+\%20 vermikulit yetiştirme ortamında yetiştirilen 1+0 yaşlı fistıkçamı fidanlarının KBÇ’na kap hacminin önemli etkide bulunduğu ve büyük hacimli kaplarda yetişen daha büyük kök boğazı çapına sahip olduğu tespit edilmiştir. Bu konuda, South vd. (2005) kök boğazı çapı ile kök geliştirme potansiyeli arasında pozitif yönde önemli bir ilişki olduğuna vurgu yapmaktadır.

Deligöz ve Gür (2015) Isparta Eğridir fidanlığında fistıkçamı üzerinde farklı sulama aralıklarının 1+0 yaşlı tüplü fidan morfolojisine ve fizyolojisine etkisini araştırdıkları çalışmalarında; kontrol grubuna ait morfolojik verileri; 17,24 cm boy, 3,58 cm çap, 47,88 boy/çap (GI), 2,63 katlılık ve \%28 kuru kök yüzdesi değerlerini gözlemişlerdir. $\mathrm{Bu}$ değerler arasındaki 2,63 katlılık ve \%28 \%Kkök değerleri, bu çalışmanın yürütüldüğü Samsun-Gelemen orman fidanlığındaki $2+0$ ve $3+0$ yaşlı tüplü fidanlardan daha uygun olduğu görülmektedir. Zira, $2+0$ yaşlı fidanlarda Kİ 4,99, \%Kkök ise 17, 3+0 yaşlı fidanlarda ise Kİ 5,61, \%Kkök ise 16 olarak saptanmıştır. Bilir vd. (2010) tarafından Aydın-Koçarlı orijinli 15 farklı ailenin açık tozlaşma ürünü tohumları ile Isparta-SDÜ Atabey Meslek Yüksekokulu uygulama fidanlığında yürüttükleri bir başka araştırmada ise 2+0 yaşlı çıplak köklü fıstıkçamı fidanlarında ortalama FB 22,9 cm, KBÇ 4,4 mm ve Kİ ise 5,4 olarak tespit etmişlerdir.

Tolay (1983), Kİ değerinin, gövde ve kök arasında uyum gösterdiğini ve fidanın arazi başarısı hakkında kanaat oluşturduğunu ifade etmektedir. Bernier vd. (1995) ise Kİ değerinin genellikle çıplak köklü fidanlarda ve nadiren de kaplı fidanlarda kalite kriteri olarak kullanıldığını belirterek, gövde/kök oranının yüksek olması, köklerin bol 
olmadığı anlamına geldiğini ve özellikle kurak alanlarda ya da yüksek buharlaşma koşullarında yapılan dikimlerde fidanların su stresinden olumsuz etkilenebileceğini bildirmektedir. Gövde/kök oranının düşük olması ise köklerin yaprak alanına göre bol olduğunu ve fidanların yüksek su stresine dayanma potansiyelini göstermektedir. Eyüboğlu (1979), Kİ bitkinin fizyolojik durumu üzerinde daha fazla etkili olduğunu, bu nedenle ekstrem iklim koşullarında ve kurak alanlarda tutma başarısını arttırmak için bu oranın en fazla 3 olması gerektiğini vurgulamaktadır. Kİ değerinin 3'ün altında olması halinde kuraklık ölümlerinin daha az olacağını dile getirmiştir. Tarafımızca yürütülen bu araştırmadaki tüplü fidanların Akdeniz havzasındaki karasal iklime sahip alanlar ile kurak ve yarı kurak alanlar için uygun nitelikte fidanlar olmadığı söylenebilir.

Kılcı vd. (2014) doğal fistıkçamı ormanlarının, Akdeniz ikliminin etkisi altında bulunan bölgelerde yer almakla birlikte özel konumu, toprakları, doğal bitki örtüsü ve iklim özellikleri değerlendirildiğinde, bu sahaların lokal özellik taşıdığını belirlemişlerdir. Bu bilgiler doğrultusunda fistıkçamının toprak, su, iklim istekleri açısından kanaatkâr olmadığı, bilakis seçici bir tür olduğu bildirilmektedir. Bu yüzden kurak ve yarı kurak bölgeler de yapılacak ağaçlandırmalar için uygun bir tür olmadığı belirtilmiştir. Dirik (1994) tarafından kızılçam, karaçam ve fistıkçamının kuraklığa karşı reaksiyonlarını belirlemek amacıyla yürütülen çalışmada ise transpirasyonla oluşan su kayıplarına karşı en iyi direnci kızılçamın gösterdiği, bu türü Anadolu karaçamı ve fıstıkçamının izlediğini, ekofizyolojik bakımdan kızılçamın kuraklık etkilerine karşı yüksek bir dayanıklılık potansiyeline sahip iken fıstıkçamının ise sınırlı kuraklık etkilerine uyum gösterebilen bir tür olduğu ifade edilmiştir.

Tablo 4 incelendiğinde; $2+0$ ve $3+0$ yaşlı tüplü fistıkçamı fidanlarının tamamı FB kriteri açısından TSE standartlarına göre 1. kalite sınıfında olduğu belirlenmiştir. KBÇ kriteri açısından ise 3+0 yaşlı fidanların tamamı, $2+0$ yaşlı fidanların ise \%96,7'si 1 . kalite sınıfında olduğu tespit edilmiştir. Kİ kriteri açısından $2+0$ yaşlı fidanların \%76,7'si, 3+0 yaşlı fidanların ise \%90’1 “Iskarta” vasfındadır. Bu durum, yetiştirilen tüplü fistıkçamı fidanlarının arzu edilen gövde-kök dengesine diğer bir ifadeyle Kİ değerine sahip olmadığını, potansiyel olarak yüksek buharlaşmanın olabileceği kurak-yarı kurak alanlarda su stresinden olumsuz etkileneceğine işaret etmektedir. Aphalo ve Rikala (2003)'nın Gİ değerine göre yapılan kalite sınıflamasına göre ise $2+0$ yaşlı tüplü

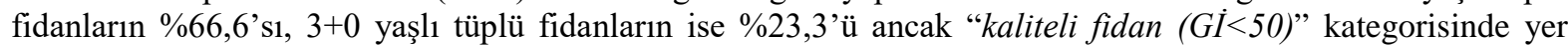
almıştır.

Tablo 4. Fıstıkçamı fidanlarında; fidanların kalite kriterleri, sınıfları ve yüzdeleri.

\begin{tabular}{|c|c|c|c|c|c|c|}
\hline \multirow{3}{*}{ Yaş } & \multirow{3}{*}{ Kalite Sinıfı } & \multicolumn{5}{|c|}{ Fıstıkçamı } \\
\hline & & \multicolumn{4}{|c|}{ TSE'ye göre } & \multirow{2}{*}{$\begin{array}{c}\text { Gं́ } \\
\text { Aphalo ve Rikala (2003)'ya göre } \\
\text { Adet } \% \\
\end{array}$} \\
\hline & & $\begin{array}{c}\text { FB } \\
\text { Adet/\% }\end{array}$ & $\begin{array}{c}\text { KBÇ } \\
\text { Adet / \% }\end{array}$ & $\begin{array}{c}\text { KI } \\
\text { Adet / \% }\end{array}$ & $\begin{array}{c}\text { FB-KBÇ-Kİ } \\
\text { Adet/\% }\end{array}$ & \\
\hline \multirow{3}{*}{$2+0$} & I. Sinıf & $30 / 100$ & $29 / 96,7$ & - & $8 / 26,6$ & $20 / 66,6$ \\
\hline & II. Sinıf & - & - & $7 / 23,3$ & $1 / 3,3$ & $6 / 20$ \\
\hline & Iskarta & - & $1 / 3,3$ & $23 / 76,7$ & $21 / 70,1$ & $4 / 13,3$ \\
\hline \multirow{3}{*}{$3+0$} & I. Sinıf & $30 / 100$ & $30 / 100$ & $1 / 3,3$ & $1 / 3,3$ & $7 / 23,3$ \\
\hline & II. Sinıf & - & - & $2 / 6,7$ & $2 / 6,7$ & $11 / 36,7$ \\
\hline & Iskarta & - & - & $27 / 90$ & $27 / 90$ & $12 / 40$ \\
\hline
\end{tabular}

\section{Sonuc}

Fıstıkçamı, Türkiye'deki doğal yayılışını ağırlıklı olarak Ege ve Batı Akdeniz olmak üzere Doğu Akdeniz, Marmara, Batı ve Doğu Karadeniz bölgelerinde oldukça dağınık ve küçük popülasyonlar şeklinde gerçekleştirmektedir. Başta ekonomik önemi nedeniyle odun dışı ürün olarak fistık üretimi amacıyla pek çok farklı plantasyonu yapılan fıstıkçamı fidanlarının mutlak suretle kullanılacağı bölge ve ağaçlandırma gayesi dikkate alınmalı ve ayrıca fidan yaşı ve tipine göre fidan standartlarının oluşturulması gereklidir. Bu durum yüksek ağaçlandırma performansı için önem arz etmektedir. Aynı hacimdeki polietilen tüplerde ve aynı yetiştirme ortamında yetiştirilen tüplü fıstıkçamı fidanlarında birçok morfolojik özellik bakımından görülen büyük varyasyonlar dolayısıyla heterojen nitelikteki fidan üretimi, bu çalışmada dikkat çeken bir husustur. Ayrıca aşırı boy ve gövde gelişimine karşın, düşük KKA, \%Kkök ve uygun olmayan kök-gövde dengesi gibi kök gelişimi zayıflığı nedeniyle fidanlara, su stresi ile koşullandırma, fidanlık ekolojisine özgü fidan gelişim dönemlerini esas alan kök kesimi, gübreleme ve sulama rejimi gibi kültürel işlemlerin doğru ve etkin bir şekilde uygulanmasına daha büyük önem verilmesini gerektirmektedir. Bu araştırma ile morfolojik özellikleri ortaya konan mevcut standartlardaki fıstıkçamı fidanlarının ancak dikim sonrası kültürel bakım çalışmalarının entansif bir şekilde yapılabildiği peyzaj düzenleme amaçlı ağaçlandırmalarda kullanılabileceği düşünülmektedir. 


\section{Kaynaklar}

1. Anonim, (1988). TS 2265/Şubat 1988 İğne Yapraklı Ağaç Fidanları Standardı, Türk Standartları Enstitüsü, Ankara.

2. Anonim, (2013). Yeşilırmak Havzasında Kırsal Nüfusun Odun Dış1 Orman Ürünleri Farkındalığ1 (KORUP)” Projesi. (Amasya, Çorum, Samsun, Tokat) Odun Dışı Orman Ürünleri Envanteri Kitabı, 168 s. Erişim [http://www.yesilirmak.org.tr/userfiles/file/ODOU KORUP.pdf]

3. Aphalo, P., Rikala, R., (2003). Field Performance of Silver-Birch Planting-Stock Grown at Different Spacingand in Containers of Different Volume, New Forests 25: 93-108, Kluwer Academic Publishers. Printed in The Netherlands.

4. Avanoğlu, B., Ayan, S., Demircioğlu, N., Sivacioğlu, A. (2005). The Evaluation of 2+0-year old Black pine (Pinus nigra Arnold. subsp. pallasiana (Lamb.) Holmboe.) seedlings produced in KastamonuTaşköprü Forest Nursery according to the norms of Turkish Standards Institution, SIGMA: Journal of Engineering and Science, Y1ldı Technical University, 2, 73-83, İstanbul.

5. Avşar, M.D. (2000). Kahramanmaraş yöresi fistıkçamı (Pinus pinea L.) meşcereleri üzerine bir araştırma, Orman Bakanlığı yayın no. 114, Müdürlük yayın no. 21, Ege Ormancılık Araştırma Müdürlüğ̈̈ Yayınlarl, Dergi Serisi, 1: 41-50.

6. Awada, T., Radoglou, K., Fotelli, M.N., Constantinidou, H.I.A., (2003). Ecophysiology of seedlings of three Mediterranean pine species in contrasting light regimes. Tree Physiology, 23:33-41.

7. Ayan, S. (1999). The effects of slow release fertilizer on the production of Containerized-Scotch Pine (Pinus sylvestris L.), Journal of Forest Engineering, 35 (9), 25-28, Ankara.

8. Ayan, S., Sivacioğlu, A. (2006). Review of the fast growing forest tree species in Turkey, The Bulletin CIDEU, 2: 57-71.

9. Ayıntaplı P., (1995). Serinyol ve Tekir fidanlıklarında üretilen Kızılçam, Anadolu Karaçamı ve Toros Sediri fidanlarında kalite sınıflaması araştırmaları. Yüksek Lisans Tezi, KTÜ Fen Bilimleri Enstitüsü, 116 s. Trabzon.

10. Barbero, M., Loiser, R., Queze,l P., Richardson, D.M., Romane, F. (1998). Pines of the Mediterranean basin. In: Richardson DM (ed) Ecology and Biogeography of Pinus. Cambridge University Press, Cambridge.

11. Bazzaz, F.A., Ackerly, D.D., Reekie, E.G. (2000). Reproductive allocation in plants. In: Fenner M (ed) Seeds: the ecology of regeneration in plant communities, 2nd edn. CAB International, Wallingford.

12. Bernier, P.Y., Lamhamedi, M.S., Simpson, D. G., (1995). Shoot:Root Ratio Is of Limited Use in Evaluating the Quality of Container Conifer Stock. Tree Planters' Notes 46 (3), 102-106.

13. Bilgin, S. (2008). Fıstıkçamı (Pinus pinea L.)'nın tohum-fidan ilişkileri ve fidanlıkta fidan yetiştirme teknikleri. Doktora tezi, Süleyman Demirel Üniversitesi, Fen Bilimleri Enstitüsü, Isparta.

14. Bilgin, S. (2019). Fıstıkçamı (Pinus pinea L.), palamut meşesi (Quercus ithaburensis Decne. subsp. macrolepis (Kotschy) Hedge \& Yalt.) ve saçlı meşe (Quercus cerris L.) fidanlarının fidan kalite özelliklerinin belirlenmesi. Turkish Journal of Forestry, 20(4):297-304.DOI: 10.18182/tjf.565999

15. Bilir, N., Kaya, C., Ulusan, M.D. (2010). Aydın Orijinli Fıstıkçamı (Pinus pinea L.) Fidanlarında Morfolojik Özellikler ve Fidan Kalitesi, Kastamonu Üni., Orman Fakültesi Dergisi, 10 (1): 37-43.

16. Calado, N. (2012). Fileira da pinha/pinhão: necessidades de informação e conhecimento. Seminário UNAC de Valorização da Fileira da Pinha/Pinhão, Alcácer do Sal, September 18, 2012.

17. Carrasquinho, I., Gonçalves, E. (2013). Genetic variability among Pinus pinea L. provenances for survival and growth traits in Portugal. Tree Genet Genomes 9:855-866. doi:10.1007/s11295-013-06032.

18. Çetinkaya, D., Bilir, N. (2019). Toros Sediri’nde (Cedrus libani A. Rich.) Fidan Tipi x Fidan Morfolojisi Etkileşimi. Mehmet Akif Ersoy Üniversitesi Fen Bilimleri Enstitüsü Dergisi 10(1): 28-33. ISSN Online: 1309-2243, http://dergipark.gov.tr/makufebed, https://doi.org/10.29048/makufebed.510959.

19. Deligöz A. (2007). Anadolu karaçamı (Pinus nigra arn. subsp. pallasiana (Lamb.) Holmboe) fidanlarına ait bazı temel morfolojik ve ekofizyolojik özelliklerin dikim başarısına etkisi. Doktora Tezi, SDÜ Fen Bilimleri Enstitüsü, 295 s. Isparta

20. Deligöz, A., Gur, M. (2015). Morphological, physiological and biochemical responses to drought stress of Stone pine (Pinus pinea L.) seedlings. Acta physiologiae plantarum, 37(11), 243.

21. Demircioğlu, N., Ayan, S., Avanoğlu, B., Sivacioğlu, A. (2004). The Evaluation of 2+0-year old Scotch pine (Pinus sylvestris L.) seedlings produced in Kastamonu-Taşköprü Forest Nursery according to the norms of Turkish Standards Institution, Journal of Engineering, Faculty of Engineering, Pamukkale University, 2 (10) 243-251, Denizli.

22. Dickson, A., Leaf, A.L., Hosner, J.F. (1960). Quality appraisal of white spruce and white pine seedlings stock in nurseries. Forestry Chronicle, 36(1):10-13. 
23. Dirik, H. (1994). Üç yerli çam türünün (Pinus brutia Ten., Pinus nigra Arn. ssp. pallasiana Lam., Pinus pinea L.) kurak periyoddaki transpirasyon tutumlarının ekofizyolojik analizi. İ. U. Orman Fakültesi Dergisi. 44A(1): 111-121.

24. Dominguez Lerena, S., Herrero Sierra, N., Carrasco Manzano, I., Ocana Bueno, S., Penuelas Rubira, J. L., Mexal, J.G. (2006). Container characteristics influnce Pinus pinea seedling devolpoment in the nursery and field. Forest Ecology and Management, 221, 63-71.

25. Eler, Ü., Keskin, S., Örtel, E. (1993). Toros sediri (Cedrus libani A. Rich.) Fidanlarında Kalite Sınıflarının Belirlenmesi Üzerine Araştırmalar. Ormancılık Araştırma Enstitüsü Dergisi, 240:81-105.

26. Eyüboğlu, A. K. (1979). Fidan. Ormancılık Araştırma Enstitüsü Dergisi, 50, 31-69s,

27. Fady, B., Fineschi Vendramin, G.G. (2004). EUFORGEN Technical Guidelines for genetic conservation and use for Italian stone pine (Pinus pinea). International Plant Genetic Resources Institute, Rome, Italy. 6 pages. ISBN 92-9043-663-8.

28. Farjon, A. (2013). Pinus pinea (errata version published in 2018). The IUCN Red List of Threatened Species 2013: $\quad$ e.T42391A129160976. http://dx.doi.org/10.2305/IUCN.UK.20131.RLTS.T42391A2977175.en

29. Fırat, F. (1943). Fıstıkçamı ormanlarımızda meyve ve odun verimi bakımından araştırmalar ve bu ormanların amenajman esasları. Yüksek Ziraat Enstitüsü Yayınları, 141, Ankara.

30. Ganatsas, P., Tsakaldimi, M., Thanos, C. (2008). Seed and cone diversity and seed germination of Pinus pinea in Strofylia Site of the Natura 2000 Network. Biodivers Conserv, 17:2427-2439

31. Garcia Vargas, J.F., Baciller Catalan, G.Y. (2000). The Fao-Ciheam Interregional Cooperative Research Network On Nuts. 1'er Simposia Del Pino Pinonero (Pinus pinea L.), Tomo II, 22-24 Febrero 2000, 363-370, Spain.

32. Genç, M. (1992). Doğu ladini (Picea orientalis (L.) Link.) fidanlarına ait bazı morfolojik ve fizyolojik özelliklerle dikim başarısı arasındaki ilişkiler. Yayınlanmamış Doktora Tezi, KTÜ Fen Bilimleri Enstitüsü. Trabzon.

33. Genç, M. (2004). Silvikültürün Temel Esasları. SDÜ Orman Fakültesi yayınları No: 44, Isparta.

34. Gezer A., Aslan S.(1980). Güneydoğu Anadolu Bölgesinde İyi Gelişim Gösteren Bazı İğne Yapraklı Ağaç Türlerinin Seçimi Üzerine Araştırmalar. OAE Yayınları Teknik Bülten Serisi No:103, Ankara.

35. Gezer, A. (1976). Ağaçlandırmalarda Kullanılmaya Elverişli Doğu Ladini (Picea orientalis (L.) Link.) Fidanlarının Bazı Morfolojik Yapılarına Göre Tespiti ve Bunun Sonucunda Bulunacak Elverişli Tipteki Fidanların Fidanlıklarda Üretim Oranını Arttırma Üzerine Araştırmalar. OAE Teknik Bülten Serisi No: 91, Ankara.

36. Gilman E.F., Watson, D.G. (1994). Pinus pinea: Stone Pine, Fact Sheet ST-472, October 1994, USDA Forest Services. http://hort.ufl.edu/database/documents/pdf/tree_fact_sheets/pinpina.pdf.

37. Gülseven, O., Ayan, S., Özel, H. B., Yer, E. N. (2019). Farklı doğu kayını (Fagus orientalis Lipsky.) populasyonlarına ait fidanların morfolojik ve fizyolojik karakteristikleri. Türkiye Ormancılık Dergisi, 20(3): 180-186. Isparta.

38. Kılcı, M., Akbin, G., Sayman, M. (2014). Fıstık Çamı (Pinus pinea L.). Ege Ormancılık Araştırma Enstitüsü Müdürlüğ̈̈ Yayın No: 74, ISBN 978-605-4610-59-4, İzmir.

39. Kırdar, E., Özel, H.B., Ertekin, M. (2010). Fıstıkçamı (Pinus pinea 1.) ağaçlandırmalarında budama uygulamasının boy ve çap gelişimi üzerine etkileri, Bartın Orman Fakültesi Dergisi, 12 (18) 1-10.

40. Kızmaz, M. (1993). Karaçam Fidanlarının Kalite Sınıflarının Belirlenmesi Üzerine Araştırmalar. Ormancılık Araştırma Enstitüsü Yayınları, Teknik Bülten No: 238-241, 7-36.

41. Lawerence, W.S. (1993). Resource and pollen limitation: plant size-dependent reproductive patterns in Physalis longifolia. Am Nat 141:296-313. doi:10.1086/285474.

42. Moussouris, Y., Regato P. (1999). Forest harvest: an overview of non timber forest products in the Mediterranean Region. http://www.fao.org/docrep/x5593e/x5593e00.htm.

43. Mutke, S. (2011). Toward a traceability of European pine nuts ' from forest to fork'. International meeting on mediterranean stone pine for Agroforestry, Valladolid-Spain, 17-19 November 2011, p 33.

44. Mutke, S., Calama, R., González-Martínez, S.C., Montero, G., Gordo, J., Bono, D., Gil, L. (2012). Mediterranean Stone Pine: Botany and Horticulture. Horticultural Reviews 39: John Wiley \& Sons, Inc., Hoboken, New Jersey:153-201. ISBN: 978-1-1180-9678-9

45. Mutke, S., Fady, B., Ben, M.N.A., Khaldi, A., Khouja, M.L. (2011). Stone pine provenance trials in France, Spain, and Tunisia. International Meeting on Mediterranean stone pine for Agroforestry, Valladolid-Spain, 17-19 November 2011, p 31.

46. OGM, (2006). Fistıkçamı Eylem Planı (2006-2010). Orman Genel Müdürlüğü, Ankara.

47. Perula, V.G., Cerrillo, R.M.N., Rebolloo, P.F., Murillo, G.V. (2003). Postfire regeneration of Pinus pinea L. and Pinus pinaster Aiton in Andalusia (Spain). Environ Manage 31:86-99. doi:10.1007/s00267-002-2786-4. 
48. Quétzel, P., Médail, F. (2003). Ecologie et biogéographie des forêts du bassin méditerranéen. Collection Environnement. Elsevier, Paris, 572 p. ISBN 2-84299-451-5.

49. Ramsey, M. (1997). No evidence of demographic costs of seed production in the pollen-limited perennial herb Blandfolia grandiflora (Liliaceae). Int J Plant Sci 158:785-793. doi:10.1086/297491.

50. Rodrigo, A., Quintana, V., Retana, J. (2007). Fire reduces Pinus pinea distribution in the northeastern Iberian Peninsula. Ecoscience 14:23-30. doi:10.2980/1195-6860(2007) 14[23:FRPPDI]2.0.CO;2.

51. Sayman, M., Akbin, G., Kılcı, M. (2006), How suitable is the stone pine (Pinus pinea) species for plantation in arid and semi-arid regions? Workshop on evaluation of afforestation and erosion practices in semi-arid regions of Turkey, 7-10 November 2006, pp 343-352, Ürgüp.

52. South, D.B., Haris, S.W., Barnett, J.P., Hainds, M.J., Gjerstad, D.H., (2005). Effect of container type and seedling size on survival and early height growth of Pinus palustris seedlings in Alabama, USA, Forest Ecology and Management, 204 (2-3) 385-398.

53. Tapias, R., Climent, J., Pardos, J.A., Gill, L. (2004). Life histories of Mediterranean pines. Plant Ecol 171:53-68.doi:10.1023/B:VEGE.0000029383.72609.f0

54. Thompson, B.E. (1985). Seedling Morphological Evaluation: What You Can Tell by Looking, Evaluating Seedling Quality: Principles, Procedures, and Predictive Ability Of Major Tests, Editor: Duryea M.L., Oregon State University, Corvallis, 55-71.

55. Tolay, U. (1983). Hendek Orman Fidanlığında Uludağ Göknarı (Abies bornmülleriana Mattf.)'ın Yetiştirilmesi Tekniği ile Fidan Kalitesi ve Dikim Başarısı Arasındaki İlişkiler Üzerine Araştırmalar. Kavak ve Hızlı Gelişen Tür Orman Ağaçları Araştırma Enstitüsü, Yıllık Bülten No: 19, 49-448, İzmit.

56. Ürgenç, S. (1986). Ağaçlandırma Tekniği. IÜ Orman Fakültesi Yayını, Üniversite Yayın No: 3314, Fakülte Yayın No: 375, 525s. İstanbul.

57. Villar-Salvador, P., Planelles, R., Enrıquez, E., Penuelas Rubira, J. (2004). Nursery cultivation regimes, plant functional attributes, and field performance relationships in the mediterranean oak (Quercus ilex L.). For Ecol Manag 196:257-266. doi:10.1016/j.foreco.2004.02.061.

58. Yaltırık, F. (1988). Gymnospermae (Açık Tohumlular). İ.Ü.Yayınları, 3443 (386), Taş Matbaası, İstanbul.

59. Yer, E. N., Ayan, S. (2011). Eskişehir Orman Fidanlık Koşullarında Yetiştirilen Çıplak Köklü Toros Sediri ve Anadolu Karaçam Fidanlarının Gelişim Dönemleri, K. Ü. Orman Fakültesi Dergisi, 11 (2):219- 227, Kastamonu.

60. Yılmaz, M., Tonguc, F., Bozali, N. (2010). Kahramanmaraş-Önsen doğal fistıkçamı ormanı üzerine genel bir değerlendirme, III. Ulusal Karadeniz Ormancılık Kongresi, Cilt: III, s.895- 904. Artvin. 